\title{
Dynamic contrast enhanced MRI as a predictor of vascular-targeted photodynamic focal ablation therapy outcome in prostate cancer post-failed external beam radiation therapy
}

\author{
Tristan Barrett, PhD; ${ }^{*}$ Sean R.H. Davidson, PhD; ${ }^{\dagger}$ Brian C. Wilson, MD; ${ }^{\dagger}$ Robert A. Weersink, PhD; ${ }^{;}$ \\ John Trachtenberg, MD, FRCSC,* Masoom A. Haider, MD, FRCPC ${ }^{f}$
}

*Department of Medical Imaging, University Health Network, Toronto, ON; ‘ Division of Biophysics and Bioimaging, Ontario Cancer Institute, University Health Network, Toronto, ON; §Laboratory for Applied Biophysics, Ontario Cancer Institute, University Health Network, Toronto, ON; *Division of Urology, Department of Surgical Oncology, University Health Network, Toronto, ON; £Department of Medical Imaging, Sunnybrook Health Sciences Centre and University of Toronto, Toronto, ON

Cite as: Can Urol Assoc J 2014;8(9-10):e708-14. http://dx.doi.org/10.5489/cuai.2176 Published online October 22, 2014.

\section{Abstract}

Introduction: Photodynamic therapy (PDT) can be employed as a focal therapy for prostate cancer. Dynamic contrast-enhanced (DCE) magnetic resonance imaging (MRI) can potentially help identify tumour recurrence after failed external-beam radiotherapy (EBRT). The purpose of this study was to determine the ability of DCE-MRI to predict early response to PDT salvage treatment.

Methods: Patients with post-EBRT prostate cancer recurrence were prospectively enrolled into a Phase I/II trial of PDT using WST09. A 15-patient subgroup of this cohort undergoing 1.5T DCE-MRI at baseline and 1-week post-PDT was retrospectively analyzed. The reference standard was prostate biopsy obtained 6 months post-PDT. Analysis was performed on a patient-by-patient basis, by prostate gland halves, and by prostate sextants.

Results: Biopsy 6 months post-PDT identified cancer in 10/15 patients $(66.7 \%)$, and in $24 / 90$ sextants $(26.7 \%)$. Residual cancer was identified in $22 / 37$ sextants (59.5\%) identified as being involved at baseline. DCE-MRI at 1 week correctly predicted recurrent disease with a sensitivity of $100 \%(10 / 10)$, specificity of $60 \%(3 / 5)$, positive predictive value of $83.3 \%(10 / 12)$, negative predictive value of $100 \%(3 / 3)$, and an overall accuracy of $86.7 \%$, (13/15). When analysis was performed on prostate halves, the sensitivity and negative predictive value remained at $100 \%$, with an improvement in specificity to $88.2 \%$ (15/17). The overall accuracy of DCE-MRI was similar regardless of analysis method: $86.7 \%$ on a patient-by-patient basis, $86.7 \%$ by prostate half and $83.3 \%$ by sextant. Changes in prostate-specific antigen (PSA) did not correlate to response.

Conclusion: DCE-MRI shows promise as a tool to predict successful outcome when performed 1 week post-PDT and could potentially be used to inform the need for re-treatment at an early time-point.

\section{Introduction}

External beam radiotherapy (EBRT) is an established radical treatment option for localized low-volume prostate cancer., ${ }^{1,2}$ However, despite recent advances in delivery, the rate of biochemical failure remains significant. In a large series, Kuban and colleagues reported a biochemical failure in a third of patients treated with EBRT, ${ }^{3}$ with published rates elsewhere ranging from $22 \%$ to $69 \%{ }^{4,5}$ In patients with isolated local recurrence of prostate cancer, salvage therapy offers the only chance for cure. Salvage radical prostatectomy is able to offer long-term cancer control, with $30 \%$ to $40 \%$ of patients disease free at 10 years, ${ }^{6,7}$ but the surgery is often technically challenging and associated with significant complications. ${ }^{8,9}$ Androgen deprivation therapy is often used following ERBT failure, but it is not curative. Brachytherapy, although typically a first-line treatment, has started to be employed following EBRT failure. More recently there has been a trend to use less invasive approaches, such as cryotherapy and high intensity focused ultrasound (HIFU), to increase the efficacy/risk ratio in treating local recurrence after EBRT. ${ }^{10}$

Photodynamic therapy (PDT) is another minimally invasive technique, combining injection of an intravenous photosensitizing agent with exposure of the target to light, to produce reactive oxygen species and induce cell death. Palladium-bacteriopheophorbide (WST09, Steba-Biotech N.V., The Hague, Netherlands, and Negma, Toussus-leNoble, France) is a PDT agent which has demonstrated promising results in Phase I and II trials for prostate cancer. ${ }^{11-14}$ The agent induces vascular occlusion, with subsequent ischemic necrosis of the targeted area. ${ }^{15,16}$ It is therefore intuitive that contrast-enhanced magnetic resonance imaging (MRI) could be used to monitor treatment response. 
Indeed, several studies have shown that contrast-enhanced MRI can successful demonstrate the extent of necrosis from other ablative techniques, such as HIFU and cryotherapy. ${ }^{17,18}$ Thus, DCE-MRI could theoretically determine efficacy of focal PDT earlier and predict longer-term response. This early knowledge could lead to early re-intervention in the appropriate setting. Therefore, the purpose of this study was to determine the feasibility of using DCE-MRI to predict the presence or absence of local residual tumour post-PDT in patients who have failed EBRT.

\section{Methods}

\section{Patients}

Patients with post-EBRT prostate cancer recurrence were prospectively enrolled into a Phase I/II trial of photodynamic therapy using WST09. ${ }^{11}$ The current study involves a retrospective analysis performed on a subgroup from this cohort. Approval was obtained from the ethics review board and all patients signed informed consent forms. Patients with cystitis and proctitis (to avoid PDT effects on the hyperemic bladder/ rectum), previous transurethral prostate resection, or concurrent hormone or chemotherapy were excluded from the study. Failed EBRT was defined on the basis of the ASTRO criteria of 3 consecutive elevations in serum prostate-specific antigen (PSA) level from a nadir value.

In total, 17 men (mean age 72.1 , range: $61-83$ ) underwent PDT with WST09. Prior to EBRT, 8 patients were classified as high risk for treatment failure (stage $>T 2 \mathrm{C}$, PSA $>20 \mathrm{ng} / \mathrm{mL}$, or Gleason $>7$ ), 3 were low risk (stage $<\mathrm{T} 2 \mathrm{~b}$, PSA $<10$, and Gleason $<7$ ), and 6 were intermediate risk (not high or low risk). Patients received EBRT at a mean dose of 75 Gy (range: 52.5-79.8). The mean PSA nadir was $3.8 \mathrm{ng} /$ $\mathrm{mL}$ (range: $0-5.8$ ), and the mean PSA value before MRI and biopsy was $5.4 \mathrm{ng} / \mathrm{mL}$ (range: 1.9-15.5). One patient was eliminated from analysis because he did not undergo a 6-month biopsy. Another patient was excluded due to microfocal disease and the fact that his tumour was not identified at baseline MRI. Therefore, in total, 15 men were included for image analysis.

\section{Photodynamic therapy}

A more detailed account of the procedure has been described previously. ${ }^{12}$ Briefly, patients were anesthetized and placed in the lithotomy position, 2 to 6 closed-end catheters (15 gauge, $20 \mathrm{~cm}$ length) were guided transperineally into the prostate, using a modified brachytherapy insertion template. Based on previous work, WST09 was infused at $2 \mathrm{mg} / \mathrm{kg}$, light delivery began 6 minutes post-infusion and lasted about 30 minutes, to achieve whole-gland ablation. ${ }^{19}$ The site of fibre placement and the expected treatment effect were determined by in-house software. ${ }^{12}$

\section{Biopsy and PSA follow-up}

PSA was obtained at baseline, 1, 3, and 6 months post-PDT. To enable healing of potential rectal thermal damage, systematic transrectal ultrasound (TRUS) biopsy was not performed until 6 months postoperatively. All pathologic specimens were reviewed by a single pathologist specialized in genitourinary pathology and familiar with prostate post-radiation effects. Each specimen was classified as containing cancer, no cancer, or indeterminate (atypical cells, or marked radiation effect, with no Gleason grade determined). Indeterminate regions were considered negative, as these were not considered to represent significant cancer. Histology results were subsequently correlated to MRI findings.

\section{Magnetic resonance imaging}

MRI examinations were performed using a 1.5-T MRI system (Echospeed, Excite, or Excite-HD; GE Medical Systems, Milwaukee, WI) with an 8-channel phased array surface coil. T1-weighted, multiplanar T2-weighted (axial slice thickness $3 \mathrm{~mm}$ ), and dynamic contrast-enhanced (DCE) T1-weighted were obtained in all patients prior to therapy, at 1 week (range 6-8 days), and 6 months post-treatment (mean 225 days, range: 178-465). For DCE-MRI, Gadopentate-diethylene triamine pentetic acid (Magnevist; Bayer Schering Pharma, Berlin, Germany) was injected at a dose of $0.1 \mathrm{mmol} / \mathrm{kg}$, at $4 \mathrm{~mL} / \mathrm{s}$ followed by a 20-mL saline flush using a power injector; 2 phases were acquired before contrast injection and 9 phases after. ${ }^{20}$

\section{Image analysis}

Tumour location was determined from the pre-treatment MRI by a radiologist (MAH), with 9 years prostate MRI reporting experience. The prostate was divided into 6 zones, three on each side (base, mid, and apex). On DCE-MRI, areas suspicious for tumour were identified as focal increased enhancement to background in the peripheral zone and increased nodular enhancement compared to background in the transition zone. This increased enhancement was determined on review of the first pass of contrast (48s after injection). ${ }^{20}$

On the 1 week MRI, necrosis was defined as nonenhancement on the dynamic contrast-enhanced images, allowing for areas of hemorrhage. Regions showing $<10 \%$ enhancement on the last DCE phase were also considered necrotic. ${ }^{11}$ The prostate volume was derived by contouring on axial T2-weighted images; a region-of-interest was drawn around the necrotic margin to calculate volume and derive the percentage volume of necrosis (Table 1). 
The baseline tumour location was correlated to the necrotic region identified on the 1 week post-treatment MRI to determine if this completely encompassed the tumour. Necrosis fully encompassing tumour was classified as successful treatment by imaging (Fig. 1), otherwise it was classified as treatment failure (Fig. 2). Focal residual enhancement in a region where baseline MRI and initial biopsy did not identify tumour was due to benign glandular tissue (Fig. 3.). Histology remained the gold standard for outcome evaluation.

\section{Statistics}

Statistical analysis was performed by using SPSS v.11 software (SPSS, Chicago, IL). Sensitivity, specificity, accuracy, and positive and negative predictive values (PPV, NPV) were calculated for individual patients, by half-gland, and by sextant location. To account for multiple regions being assessed for each patient, we used generalized estimating equation models to calculate the corresponding variances and to test for differences between methods. ${ }^{21}$ We calculated 95\% confidence intervals using the Agresti-Coull interval and assuming a binomial distribution..$^{22}$

\section{Results}

Baseline DCE-MRI identified prostate cancer in 15 men involving $37 / 90(41 \%)$ sextants. Cancer was located in the apex in 14/37, mid-gland in 16/37, and base in $7 / 37$.

Based on TRUS biopsy at 6 months, cancer was identified in $10 / 15$ patients $(66.7 \%)$ (Table 2$)$. Two patients demonstrated bilateral disease, thus cancer was present in $12 / 30$ half glands (40\%); overall, cancer was present in 24/90 sextants $(26.7 \%)$. Of the 10 patients with biopsy proven cancer, the average number of sextants involved was 2.4 (range: 1-4). Residual/ recurrent cancer was identified in $22 / 37$ sextants $(59.5 \%)$, which involved the baseline, prior to treatment. Cancer recurrence was in the apex in $8 / 22$, midgland in $7 / 22$, and base in $7 / 22$. Based on 6-month biopsy results, cancer was contiguous, involving one set of adjacent sextants in $8 / 10$ patients $(80 \%)$, suggesting that most recurrences were unifocal. In the 10 patients with residual tumour after treatment, the Gleason score was $3+3$ in 2 patients $(20 \%), 3+4$ in $6(60 \%)$, and $4+4$ in $2(20 \%)$.

The MRI performed 1 week post-therapy identified residual tumour in all 10 patients with subsequent recurrence. In the remaining 5 patients, DCE-MRI correctly predicted no residual disease in 3 patients, but incorrectly identified areas suspicious for residual disease in 2 patients. The ability of DCE-MRI to predict PDT outcome in terms of the individual patient by patient, prostate half and sextant core were comparable (Table 3). On a patient-by-patient basis, DCEMRI predicted recurrent disease with a sensitivity of $100 \%$ (10/10), specificity of $60 \%$ (3/5), PPV of $83.3 \%(10 / 12)$, NPV of $100 \%(3 / 3)$, and an overall accuracy of $86.7 \%$, (13/15). The sensitivity and NPV remained at $100 \%$ when analysis was performed on the basis of prostate halves, with an improvement in specificity to $88.2 \%$. The overall accuracy of DCE-MRI was similar regardless of analysis method, being $86.7 \%$ by patient, $86.7 \%$ by prostate half and $83.3 \%$ by sextant, thus both the presence and location of residual disease was demonstrated with reasonable accuracy.

Changes in PSA values did not correlate well with clinical response (Fig. 4), with $13 / 15$ patients $(86.7 \%)$ showing a PSA drop. The average baseline PSA value in patients with residual disease was $6.2 \mathrm{ng} / \mathrm{mL}$ (range: $2.5-15.5$ ), reducing

\begin{tabular}{|c|c|c|c|c|c|c|c|c|}
\hline Patient & $\begin{array}{c}\text { Baseline } \\
\text { prostate } \\
\text { volume }\left(\mathrm{cm}^{3}\right)\end{array}$ & $\begin{array}{c}1 \text { week } \\
\text { prostate } \\
\text { volume }\left(\mathrm{cm}^{3}\right)\end{array}$ & $\begin{array}{c}\text { Percent } \\
\text { increase in } \\
\text { volume }\end{array}$ & $\begin{array}{c}\text { Total drug } \\
\text { injected (mL) }\end{array}$ & $\begin{array}{c}\text { No. fibres } \\
\text { used }\end{array}$ & $\begin{array}{c}\text { Necrosis } \\
\text { volume at } \\
1 \text { week }\end{array}$ & $\begin{array}{c}\text { Percent } \\
\text { necrosis at } \\
1 \text { week }\end{array}$ & $\begin{array}{c}\text { Extra- } \\
\text { prostatic } \\
\text { necrosis }\end{array}$ \\
\hline 1 & 29.53 & 35.24 & 19.3 & 64.3 & 5 & 0.3 & 0.85 & No \\
\hline 2 & 29.47 & 31.28 & 6.14 & 63.5 & 5 & 2.08 & 6.64 & No \\
\hline 3 & 27.72 & 34.24 & 23.5 & 47.8 & 5 & 2.79 & 8.14 & yes \\
\hline 4 & 27.13 & 31.9 & 17.6 & 62.0 & 5 & 2.49 & 8.11 & Yes \\
\hline 5 & 25.65 & 26.64 & 3.86 & 78.6 & 4 & 2.59 & 9.72 & Yes \\
\hline 6 & 22.66 & 29.76 & 31.3 & 74.0 & 5 & 6.42 & 21.6 & Yes \\
\hline 7 & 27.50 & 32.53 & 18.3 & 60.0 & 5 & 4.99 & 15.3 & Yes \\
\hline 8 & 33.28 & 42.79 & 28.6 & 61.2 & 6 & 10.21 & 23.9 & Yes \\
\hline 9 & 6.63 & 9.36 & 41.2 & 62.7 & 2 & 4.1 & 43.8 & Yes \\
\hline 10 & 21.15 & 25.85 & 22.2 & 79.0 & 4 & 9.84 & 38.1 & Yes \\
\hline 11 & 31.50 & 36.88 & 17.1 & 74.8 & 6 & 15.1 & 40.9 & Yes \\
\hline 12 & 34.14 & 40.19 & 17.7 & 84.0 & 5 & 19.34 & 50.1 & Yes \\
\hline 13 & 30.42 & 38.17 & 25.5 & 63.6 & 6 & 23.35 & 61.2 & Yes \\
\hline 14 & 23.60 & 25.33 & 7.33 & 64.6 & 5 & 19.57 & 78.0 & Yes \\
\hline 15 & 36.75 & 37.57 & 2.23 & 66.0 & 5 & 31.52 & 83.9 & Yes \\
\hline
\end{tabular}




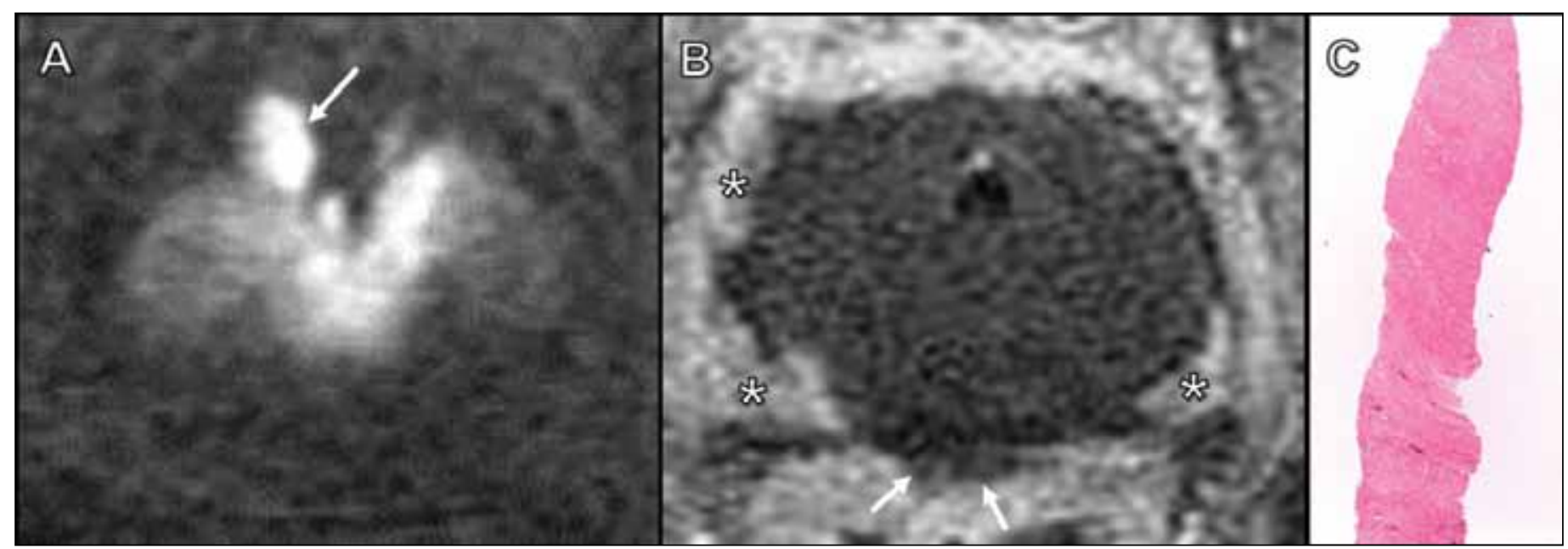

Fig. 1. Successful photodynamic therapy. A. Baseline dynamic contrast-enhanced magnetic resonance imaging (DCE-MRI) shows early enhancement in the right anterior mid gland (arrow). B. 10 minute post contrast DCE-MRI at day 7 post-treatment showing widespread non-enhancing areas of necrosis, with only small residual areas of enhancement peripherally $\left(^{*}\right)$, overall gland necrosis $=80 \%$; note an area of necrosis within the outer wall of the rectum (arrows). C. Core biopsy from the right mid gland 6 months post treatment shows complete fibrosis, with no preserved prostate stroma or tumour. Scattered small vascular channels lined by reactive endothelial cells are seen consistent with late stage reparative fibrosis following coagulative necrosis and granulation tissue formation (25× original magnification).

to $2.9 \mathrm{ng} / \mathrm{mL}$ at 6 months (range: $0.8-3.8$ ), and $5.3 \mathrm{ng} / \mathrm{mL}$ (range: $1.9-13.4$ ), reducing to $4.6 \mathrm{ng} / \mathrm{mL}$ at 6 months (range: $0-17.9)$ in patients without disease.

\section{Discussion}

DCE-MRI can localize prostate cancer after failed EBRT with an accuracy as high as $83 \%,{ }^{20,23}$ and can assess response to focal therapies with HIFU and cryotherapy. ${ }^{24}$ We have demonstrated the ability of DCE-MRI to successfully predict early outcome of photodynamic therapy with a sensitivity and NPV of $100 \%$.

The sensitivity and NPV of DCE-MRI dropped from $100 \%$ to $75 \%$ and $90.5 \%$, respectively when the analysis was performed on a sextant-by sextant basis. Possible explanations include under-estimation of tumour volume by DCE-MRI, interval tumour growth to 6-month biopsy, or sextant registration differences between the MRI reader and the person performing the biopsy. These factors would not affect analysis on prostate half or a patient-by-patient basis. From a clinical stand-point, a decision to re-treat will be based on the prediction of recurrence on a patient-by-patient basis. Even if a more focal form of therapy is considered, this would still likely involve at least half of the gland. DCE-MRI incorrectly identified areas suspicious for residual disease in 2 patients. This may relate to enhancing benign glandular tissue, or possibly that the 6-month biopsy missed a site of recurrence.

PSA levels did not appear to correlate well with the presence of residual disease. Unless $100 \%$ of the gland is ablated, any residual prostatic tissue, even if it is diseasefree, will produce PSA, thus PSA levels are unlikely to be a

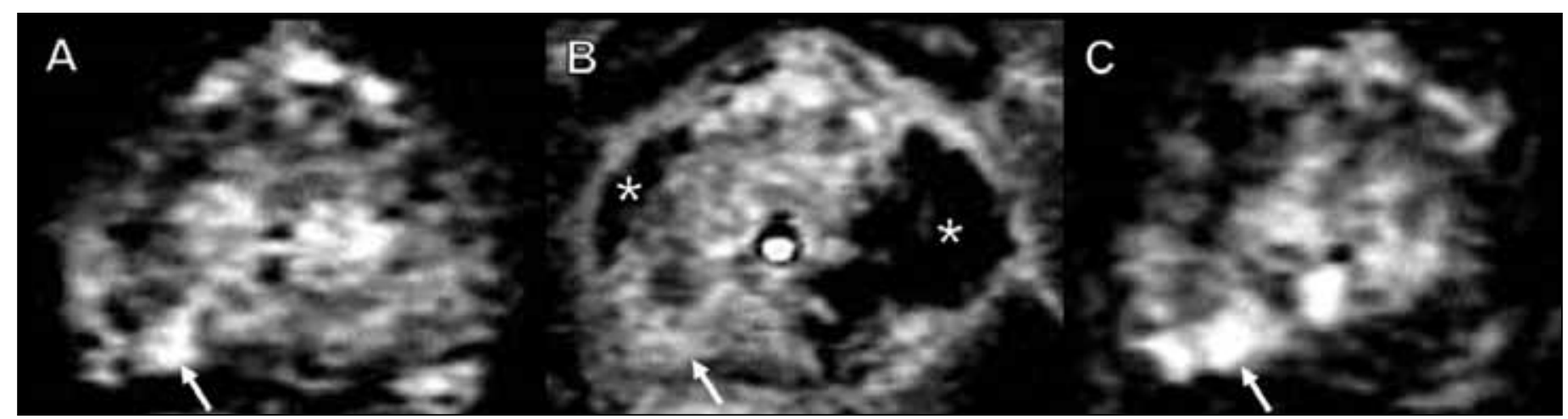

Fig. 2. Failure of photodynamic therapy predicted by dynamic contrast-enhanced magnetic resonance imaging (DCE-MRI) at day 7. A. Baseline DCE-MRI shows enhancement in the right mid gland PZ at an early time point post-contrast (arrow). B. 10 minute post contrast DCE-MRI at day 7 post-treatment showing nonenhancing areas of necrosis $\left(^{*}\right.$ ) that do not encompass tumour location from baseline (arrow) indicates treatment failure; overall gland necrosis $=22 \%$. C. DCE-MRI performed at 6 months shows area of early enhancement corresponding to location of the tumour at baseline (arrow), histology shows Gleason $3+3$ disease in the right mid, involving $20 \%$ of the core. 


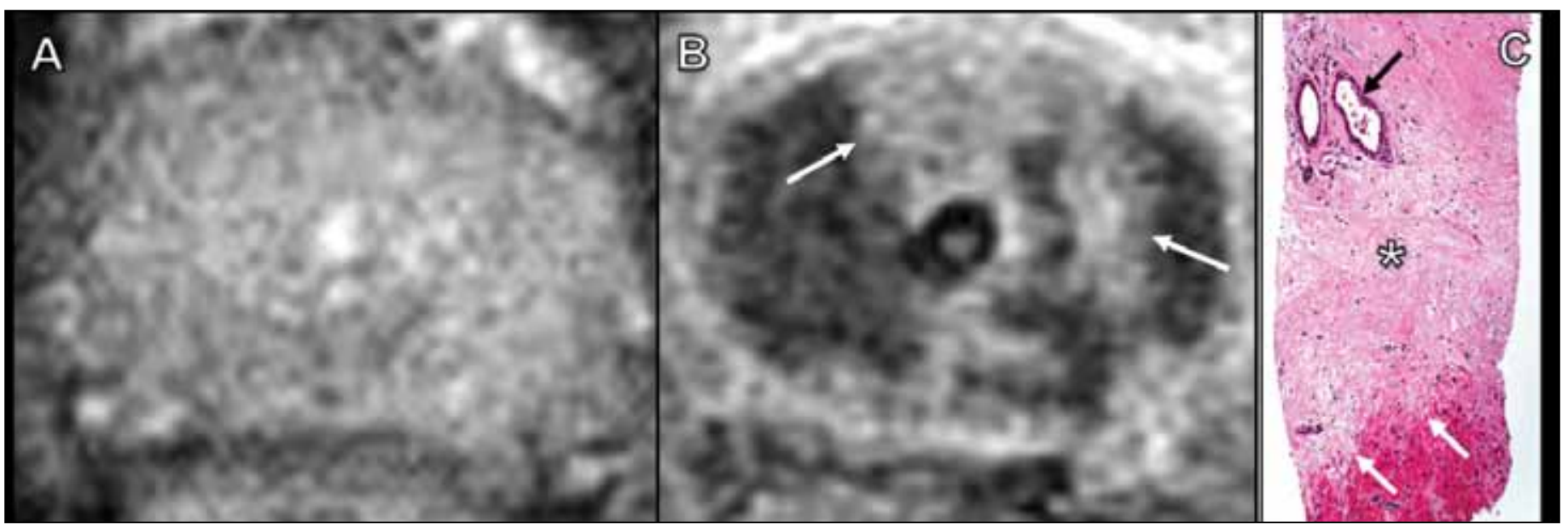

Fig. 3. Entrapped benign atrophic glands within an area of photodynamic therapy (PDT)-induced fibrosis. A. Baseline post-contrast T1-weighted imaging shows homogeneous enhancement at the level of the mid gland with no obvious tumour focus. B. 10-minute post-contrast dynamic contrast-enhanced magnetic resonance imaging at day 7 post-treatment shows non-enhancing areas of necrosis, with spared areas demonstrating enhancement (arrows), representing residual benign prostatic tissue. C. Core biopsy at 6 months post-treatment shows PDT-induced fibrosis ${ }^{*}$ ), with entrapped atrophic glands (black arrow). Note also the characteristically sharp interface between the partial PDT effect and preserved fibromuscular prostate stroma at the bottom of the figure (white arrows); (100x original magnification).

reliable discriminator of treatment failure, as demonstrated in our cohort.

PDT is less invasive than prostatectomy; therapy can usually be performed in an outpatient setting, ${ }^{25}$ and multiple therapies can be performed without the dose limitations associated with radiotherapy. Furthermore, following therapy, tumour can be readily identified by histology, showing no cytonuclear or architectural modification, in contradistinction to such treatment effects of hormonal or radiation therapy which can hinder interpretation. ${ }^{18}$ It should be noted that that WST09 has now been superseded by a more hydrophilic generation of the compound for clinical use (WST11); however, the agents retain similar pharmacodynamic properties and tissue treatment effects, ${ }^{26}$ and thus the imaging results reported are valid and would be expected to be equivalent.

Our study has some limitations, including its retrospective nature. Whole-mount histology was not used for validation; however, the nature of the study cohort precluded this. A 6-core TRUS biopsy was employed, which has potential to under-sample and miss small foci of residual tumour. This core number was due to the small gland size post-radiation

\section{Table 2. Patient demographics and clinico-pathological features at baseline and follow-up}

\begin{tabular}{|c|c|c|c|c|c|c|c|c|}
\hline Patient & Age & $\begin{array}{l}\text { Baseline } \\
\text { Gleason }\end{array}$ & TNM Stage & $\begin{array}{l}\text { PSA baseline } \\
\text { (ng/mL) }\end{array}$ & $\begin{array}{l}\text { PSA at } \\
1 \text { month } \\
\text { (ng/mL) }\end{array}$ & $\begin{array}{c}\text { PSA at } \\
6 \text { months } \\
\text { (ng/mL) }\end{array}$ & $\begin{array}{l}\text { No. positive } \\
\text { sextants }\end{array}$ & $\begin{array}{c}\text { Post-PDT } \\
\text { Gleason }\end{array}$ \\
\hline 1 & 68 & $3+3$ & T2A & 3.8 & 2.1 & 3.4 & 2 & $3+4$ \\
\hline 2 & 72 & $3+4$ & $\mathrm{~T} 1 \mathrm{C}$ & 6.8 & 1.4 & 1.8 & 2 & $4+4$ \\
\hline 3 & 63 & $3+3$ & $\mathrm{~T} 2 \mathrm{~A}$ & 3.8 & 8.0 & 3.7 & 4 & $3+4$ \\
\hline 4 & 70 & $3+3$ & T2B & 3.0 & 1.2 & 2.0 & 2 & $3+4$ \\
\hline 5 & 62 & $3+4$ & $\mathrm{~T} 2 \mathrm{C}$ & 5.2 & 1.0 & 1.8 & 2 & $3+3$ \\
\hline 6 & 72 & $3+3$ & T2B & 2.5 & 2.8 & 1.7 & 2 & $3+3$ \\
\hline 7 & 76 & $3+4$ & $\mathrm{~T} 2 \mathrm{C}$ & 6.4 & 1.7 & 2.2 & 2 & $3+4$ \\
\hline 8 & 74 & $3+3$ & $\mathrm{~T} 2 \mathrm{~A}$ & 2.1 & 1.0 & 0.6 & Negative & Negative \\
\hline 9 & 83 & $3+4$ & T1A & 15.5 & 1.7 & 3.8 & 3 & $3+4$ \\
\hline 10 & 71 & $3+3$ & T2B & 4.8 & 4.6 & 4.5 & Negative & Negative \\
\hline 11 & 74 & $3+4$ & $\mathrm{~T} 2 \mathrm{~A}$ & 5.5 & 3.9 & 8.0 & 4 & $4+4$ \\
\hline 12 & 70 & $3+4$ & $\mathrm{~T} 2 \mathrm{~A}$ & 9.6 & 0.4 & 0.8 & 1 & $3+4$ \\
\hline 13 & 75 & $3+3$ & $\mathrm{~T} 1 \mathrm{C}$ & 1.9 & 0.3 & 0.1 & Negative & Negative \\
\hline 14 & 75 & $3+4$ & $\mathrm{~T} 2 \mathrm{~B}$ & 4.5 & 0.1 & 0.0 & Negative & Negative \\
\hline 15 & 75 & $3+4$ & $\mathrm{~T} 1 \mathrm{C}$ & 13.4 & 6.2 & 17.90 & Negative & Negative \\
\hline
\end{tabular}

PSA: prostate-specific antigen; PDT: photodynamic therapy. 


\begin{tabular}{|c|c|c|c|c|c|c|}
\hline & $\begin{array}{l}\text { DCE MRI by } \\
\text { Patient }\end{array}$ & $95 \% \mathrm{Cl}$ & $\begin{array}{c}\text { DCE MRI by } \\
\text { prostate halves }\end{array}$ & $95 \% \mathrm{Cl}$ & $\begin{array}{c}\text { DCE MRI by } \\
\text { Prostate sextant }\end{array}$ & $95 \% \mathrm{Cl}$ \\
\hline Sensitivity & $100 \%(10 / 10)$ & $72.2-100$ & $100 \%(11 / 11)$ & $74.1-100$ & $75 \%(18 / 24)$ & $55.1-88.0$ \\
\hline Specificity & $60 \%(3 / 5)$ & $23.1-88.2$ & $88.2 \%(15 / 17)$ & $65.7-96.7$ & $86.4 \%(57 / 66)$ & $80-95.8$ \\
\hline PPV & $83.3 \%(10 / 12)$ & $55.2-95.3$ & $73.3 \%(11 / 15)$ & $48.0-89.1$ & $66.7 \%(18 / 27)$ & $40.1-93.3$ \\
\hline NPV & $100 \%(3 / 3)$ & 43.9-100 & $100 \%(15 / 15)$ & $79.6-100$ & $90.5 \%(57 / 63)$ & $80.7-95.6$ \\
\hline Accuracy & $86.7 \%(13 / 15)$ & $62.1-96.3$ & $86.7 \%(26 / 30)$ & $70.3-94.7$ & $83.3 \%(75 / 90)$ & $74.3-89.6$ \\
\hline
\end{tabular}

therapy and PDT, and to minimize the risks of inducing a recto-prostatic fistula. An average gland ablation of only $34.95 \%$ suggested a degree of under-treatment in the cohort, however, this is not unexpected in a Phase I/II trial. Although this is a limitation of the Phase I/II trial, this is less relevant to the current study which aims to assess the ability of MRI to predict treatment response at an early time-point. The small number of patients included has the potential to limit the statistical significance of the results, and our limited early experience in this cohort will require further validation.

\section{Conclusion}

DCE-MRI shows promise as a tool to predict successful outcome when performed 1 week post-PDT and could potentially be used to inform the need for re-treatment at an early time-point.

Acknowledgements: This work was supported by Steba Biotech, N.V., The Hague, the Netherlands, and by NIH grant \#CA33894. Funding for the cost of the MR examinations, contrast material, and image interpretations in our study was provided by Negma.

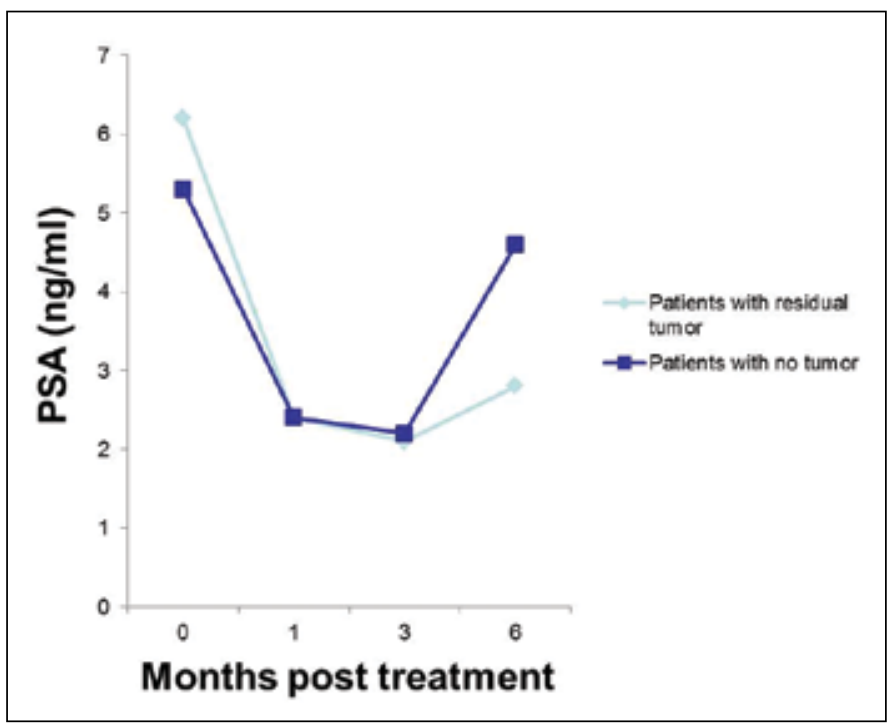

Fig. 4. Average prostate-specific antigen level at baseline, and at 1,3, and 6 months post-therapy for patients with recurrence and no residual disease on follow-up biopsy.
Competing interests: Dr. Barrett, Dr. Davidson, Dr. Wilson, Dr. Weersink, Dr. Trachtenber and Dr. Haider declare no competing financial or personal interests.

This paper has been peer-reviewed.

\section{References}

1. Arcangeli G, Strigari L, Arcangeli S, et al. Retrospective comparison of external beam radiotherapy and radical prostatectomy in high-risk, clinically localized prostate cancer. Int I Radiat Oncol Biol Phys 2009;75:975-82. http://dx.doi.org/10.1016/i.jirobp.2008.12.045

2. Horwitz EM. Why external beam radiotherapy is treatment of choice for most men with early-stage nonmetastatic prostate cancer. Urology 2009;73:470-2. http://dx.doi.org/10.1016/i.urology.2008.09.029

3. Kuban DA, Thames HD, Levy LB, et al. Long-term multi-institutional analysis of stage T1-T2 prostate cancer treated with radiotherapy in the PSA era. Int J Radiat Oncol Biol Phys 2003;57:915-28. http:// dx.doi.org/10.1016/S0360-3016(03)00632-1

4. Neppl-Huber C, Zappa M, Coebergh JW, et al. Changes in incidence, survival and mortality of prostate cancer in Europe and the United States in the PSA era: Additional diagnoses and avoided deaths. Ann Oncol 2012;23:1325-34. http://dx.doi.org/10.1093/annonc/mdr414

5. Roach M. The role of PSA in the radiotherapy of prostate cancer. Oncology (Williston Park) 1996;10:114353; discussion 1154-61.

6. Rocco B, Cozzi G, Spinelli MG, et al. Current status of salvage robot-assisted laparoscopic prostatectomy for radiorecurrent prostate cancer. Curr Urol Rep 2012;13:195-201. http://dx.doi.org/10.1007/ s1 1934-012-0245-1

7. Chade $D C$, Shariat $S F$, Cronin $A M$, et al. Salvage radical prostatectomy for radiation-recurrent prostate cancer: A multi-institutional collaboration. Eur Urol 2011;60:205-10. http://dx.doi.org/10.1016/i. eururo.2011.03.011

8. Nguyen PL, D'Amico AV, Lee AK, et al. Patient selection, cancer control, and complications after salvage local therapy for postradiation prostate-specific antigen failure: A systematic review of the literature. Cancer 2007;110:1417-28. http://dx.doi.org/10.1002/cncr.22941

9. Rogers $E$, Ohori M, Kassabian VS, et al. Salvage radical prostatectomy: Outcome measured by serum prostate specific antigen levels. J Urol 1995;153:104-10. http://dx.doi.org/10.1097/00005392199501000-00037

10. Hou AH, Sullivan KF, Crawford ED. Targeted focal therapy for prostate cancer: A review. Curr Opin Urol 2009;19:283-9. httrp://dx.doi.org/10.1097/MOU.0b013e32832a2c4a

11. Haider MA, Davidson SR, Kale AV, et al. Prostate gland: MR imaging appearance after vascular targeted photodynamic therapy with palladium-bacteriopheophorbide. Radiology 2007;244:196-204. http:// dx.doi.org/10.1148/radiol.2441060398

12. Davidson SR, Weersink RA, Haider MA, et al. Treatment planning and dose analysis for interstitial photodynamic therapy of prostate cancer. Phys Med Biol 2009;54:2293-313. http://dx.doi. org $/ 10.1088 / 0031-9155 / 54 / 8 / 003$

13. Betrouni N, Lopes R, Puech P, et al. A model to estimate the outcome of prostate cancer photodynamic therapy with TOOKAD Soluble WST1 1. Phys Med Biol 2011;56:4771-83. http://dx.doi. org/10.1088/0031-9155/56/15/009

14. Azzouzi AR, Barret E, Moore CM, et al. TOOKAD(囚) Soluble vascular-targeted photodynamic (VTP) therapy: determination of optimal treatment conditions and assessment of effects in patients with localised prostate cancer. BJU Int 2013;112:766-74. http://dx.doi.org/10.1111/bju.12265

15. Chen $Q$, Huang $Z$, Luck $D$, et al. Preclinical studies in normal canine prostate of a novel palladium-bacteriopheophorbide (WSTO9) photosensitizer for photodynamic therapy of prostate cancers. Photochem Photobiol 2002;76:438-45. http://dx.doi.org/10.1562/0031-8655(2002)076<0438:PSINCP>2.0.C0;2 
Barrett et al.

16. Eymerit-Morin C, Zidane M, Lebdai S, et al. Histopathology of prostate tissue after vascular-targeted photodynamic therapy for localized prostate cancer. Virchows Arch 2013;463:547-52. http://dx.doi. org/10.1007/s00428-013-1454-9

17. Gangi A, Tsoumakidou $G$, Abdelli 0 , et al. Percutaneous MR-guided cryoablation of prostate cancer: Initial experience. Eur Radiol 2012;22:1829-35. http://dx.doi.org/10.1007/s00330-012-241 1-8

18. Kirkham AP, Emberton $M$, Hoh $I M$, et al. MR imaging of prostate after treatment with high-intensity focused ultrasound. Radiology 2008;246:833-44. http://dx.doi.org/10.1148/radiol.2463062080

19. Trachtenberg J, Bogaards A, Weersink RA, et al. Vascular targeted photodynamic therapy with palladiumbacteriopheophorbide photosensitizer for recurrent prostate cancer following definitive radiation therapy: Assessment of safety and treatment response. J Urol 2007;178:1974-9. http://dx.doi.org/10.1016/i juro.2007.07.036

20. Haider MA, Chung P, Sweet J, et al. Dynamic contrast-enhanced magnetic resonance imaging for localization of recurrent prostate cancer after external beam radiotherapy. Int I Radiat Oncol Biol Phys 2008;70:425-30. http://dx.doi.org/10.1016/i.irobp.2007.06.029

21. Leisenring $W$, Pepe $M S$, Longton $G$. A marginal regression modelling framework for evaluating medical diagnostic tests. Stat Med 1997;16:1263-81. http://dx.doi.org/10.1002/(SICI) 10970258(19970615)16:11<1263::AID-SIM550>3.0.C0;2-M
22. Agresti A, Coull BA. Approximate is better than 'exact' for interval estimation of binomial proportions. The American Statistician 1998;52:119-26.

23. Villers A, Lemaitre L, Haffner J, et al. Current status of MRI for the diagnosis, staging and prognosis of prostate cancer: implications for focal therapy and active surveillance. Curr Opin Urol 2009;19:274-82. htrp://dx.doi.org/10.1097/MOU.0b013e328329a2ed

24. Moman MR, van den Berg CA, Boeken Kruger AE, et al. Focal salvage guided by $T(2)$-weighted and dynamic contrast-enhanced magnetic resonance imaging for prostate cancer recurrences. Int J Radiat Oncol Biol Phys 2010;76:741-6. http://dx.doi.org/10.1016/i.ijobp.2009.02.055

25. Brown SB, Brown EA, Walker I. The present and future role of photodynamic therapy in cancer treatment. Lancet Oncol 2004;5:497-508. http://dx.doi.org/10.1016/S1470-2045(04)01529-3

26. Coleman J, Scherz A. Focal therapy of localised prostate cancer by vascular targeted photodynamic therapy with WST-11 (TOOKAD® Soluble). Eur Urol Rev 2012;72:106-8.

Correspondence: Dr. Masoom A. Haider, Sunnybrook Health Sciences Centre, 2075 Bayview Ave. Rm AG-46, Toronto, ON M4N 3M5; masoom.haider@sunnybrook.ca 